\title{
The study of forming a roll of pressed hay and the influence of its density on quality parameters
}

\author{
Vyacheslav Terentyev ${ }^{1}$, Konstantin Andreev ${ }^{1, *}$, Nikolay Anikin ${ }^{1}$, Nikolay Novikov $^{2}$, \\ Vladimir Teterin ${ }^{2}$, Dmitry Blagov ${ }^{2}$ and Sergey Mitrofanov ${ }^{2}$ \\ ${ }^{1}$ Ryazan State Agrotechnological University Named after P.A. Kostychev, Ryazan, Russia \\ 2"VIM Federal Scientific Agro-Engineering Center", Moscow, Russia
}

\begin{abstract}
Hay is one of the most valuable types of roughage in the diet of ruminants. During the winter period, animals get about half of the nutrients and digestible protein from hay. Leguminous-cereal hay is rich in protein, minerals, carbohydrates, vitamins. When harvesting hay in rolls, balers with a constant-volume pressure chamber are most often used. The roll forming process consists in continuously winding the flow of plant mass onto the core to a predetermined diameter. The process of roll formation occurs due to the gradual compaction of the roll from the outside, as a result of which rolls with a low density core are formed. Studies have shown that hay compaction from the outside leads to the fact that pressure transfer from the outer layers to the inner layers occurs with some delay (stress relaxation) and the location of stems in this case will have some significant effect on the density of hay inside the roll. Experimental studies have shown that the density of hay inside the roll also varies as for the width of the roll. In the middle part of the roll (in width), the density of hay is 2 to 3 times higher than along its edges, the zone of increased density is $0.7 \mathrm{~m}$, which is $44 \%$ of the width of the roll.
\end{abstract}

\section{Introduction}

Hay is one of the most valuable types of roughage in the diet of ruminants. Animals receive about half of the feed units and digestible protein from it in winter. Many types of hay (legumes, legumes and cereals) are rich in protein, minerals, carbohydrates, vitamins [1].

Over the past decades, the most common technology for harvesting hay both abroad and in Russia has been pressing it, in particular bale pressing. This technology allows to reduce labor costs when harvesting and transporting, and also contributes to its better storage.

However, the application of roll technology of haymaking has a limiting factor, and that is a relatively narrow range of humidity of the pressed mass (18-22\%). It is not always possible to withstand this parameter even under favorable conditions. And with a higher moisture content and a significant proportion of leguminous herbs in the composition of

*Corresponding author: kosta066@yandex.ru 
hay, the feed begins to deteriorate and processes of its "self-heating" arise, that is associated with the vital activity of microorganisms [2-4].

To prepare the pressed hay, balers are used that work as follows: the sown plant mass is selected from the roll, fed into the bale chamber and pressed, depending on the selected technology and humidity, to a density of $100-150 \mathrm{~kg} / \mathrm{m} 3$. Then the obtained compressed hay roll is wrapped with some fixing material.

When harvesting hay in rolls, balers are used with a bale chamber of variable and constant volume. The process of forming a roll in them consists in continuously winding the plant mass onto the core up to a predetermined diameter [5].

In balers with a constant-volume chamber, the pressing bodies are rollers, slat conveyors. The chamber volume is formed by a pressing mechanism. The process of roll formation occurs due to the gradual compaction of the roll from the outside, as a result of which rolls with a low density core are formed. The dried stalk mass coming from the rolls into the chamber rotates randomly until the chamber is full. The compaction of hay from the outside leads to the fact that the pressure transfer from the outer layers to the inner layers occurs with some delay (stress relaxation), the location of stems in this case will have some significant effect on the uniformity of the hay density inside the roll, which can lead to the formation of zones with low density inside the roll, which will facilitate the penetration of moisture, the development of microbiological processes and, as a consequence, reduce the safety of hay $[6,7]$.

\section{Materials and methods}

In the course of research, the process of forming a roll in a baler with a constant-volume pressing chamber was theoretically considered.

To study the density of hay inside the roll, a series of experiments was carried out during which hay of natural herbs was harvested. From a batch of rolls prepared by one baler, rolls were randomly selected and divided into plots. The insertion force of the tip was determined at the borders of sections using a Revyakin hardness tester equipped with special tips.

To obtain reliable results, trials were repeated at each boundary of the plots. These tests were averaged by the formula:

$$
h_{c p}=\frac{h_{1}+h_{2}+\ldots+h_{n}}{n}
$$

where $\mathrm{h} 1, \mathrm{~h} 2 \ldots \mathrm{hn}$ are heights of diagrams, $\mathrm{m}$.

After determining the density of the selected rolls, they were laid for storage in different tiers of the stack. After 40 days from the time of its harvesting, hay samples were taken to determine its quality parameters indicators. Hay samples were taken with the help of a sampler from the center and the periphery of each of the rolls, from all accessible sides from a depth of at least $50 \mathrm{~cm}$. From the point samples weighing from 0.1 to $0.5 \mathrm{~kg}$, a combined sample weighing $5 \mathrm{~kg}$ was made. Then a sample weighing at least $1 \mathrm{~kg}$ was extracted for analysis and it was packed in a bag of polymer film and transferred to an accredited testing laboratory for agrochemical services for agricultural production.

\section{Results and discussion}


Increasing the safety of pressed hay depends on the density distribution of stalk feed inside the roll. The process of pressing hay in rolls consists of several stages. At the initial stage of the process of movement, the cylindrical bale chamber is filled with hay. With further supply of material into the chamber tangentially to the surface of the roll, the outer layers of the roll are compressed and only then, as the compressive forces increase, its inner layers are also involved in the deformation process [8]. Thus, the compaction of the roll occurs on the outside due to the radial forces acting on the side of the sealing rollers. When reaching the maximum pressing force, the finished roll is wrapped and unloaded.

Consider hay compaction in a cylindrical bale chamber of constant volume (Figure 1)

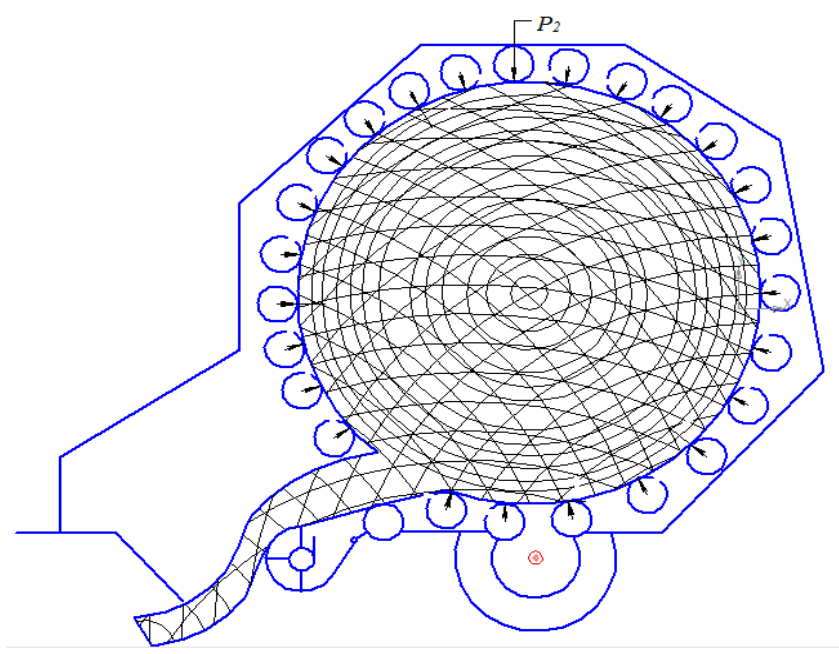

Fig. 1. The scheme for determining the density of the roll pressing.

The deformed state of the roll in this case will be axisymmetric, that is, each point of the roll will move only in the radius direction byuand parallel to the roll axis byv (Figure 2). Moreover, the deformation of hay in a roll will occur as for an elastic-viscous material according to a nonlinear law [9]. A feature of organic materials, including hay, is that during the deformation, a sharp increase in load occurs, then plastic deformation with a decrease in load and stress relaxation with repetitions happen [8]. Thus, it can be assumed that at the time of pressing the roll, the hay will be in an elastoplastic state. However, taking into account the anisotropic properties of hay and the peculiarities of roll formation, it can be assumed that the axial deformation of the roll is negligible.

Considering the fact that hay has anisotropy, one can assume that during the formation of a roll during winding outside, a center of low hay density is preserved in its center [8]. Imagine a roll loaded with pressure outside and inside. The internal pressure P1of the roll will be determined by the elasticity of the hay, and the external pressure P2by bale rollers or blades.

Consider roll element abcd formed by two concentric circles with radius $\mathrm{r}$ and $\mathrm{r}$ - $\mathrm{dr}$ and two rays drawn at angle $\theta$ and $\theta+\mathrm{d} \theta$ to $\mathrm{Ox}$ axis in polar coordinates, for simplicity of calculations, we conventionally equate the thickness of the element to one (Figure $2 \mathrm{a}, \mathrm{b}$ ).

Let us denote the radial movement of an arbitrary point of an infinitesimal element in the direction to the center of the rollu, as well as its circumferential movementv. In this case, the relative compression (downsizing)erof side ab of the element is called radial deformation, and relative compression $\varepsilon \theta$ of arc bc is called circumferential deformation. 


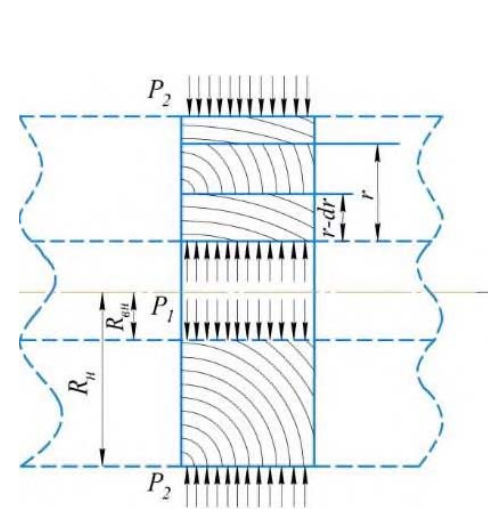

a)

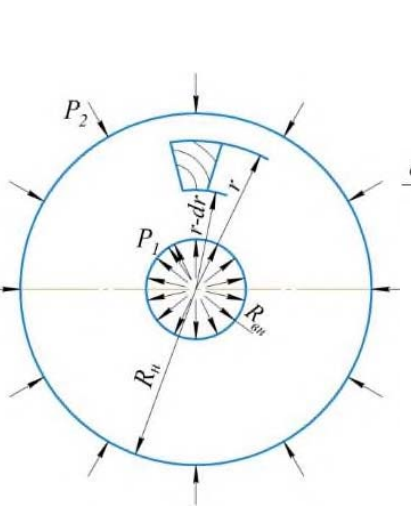

b)

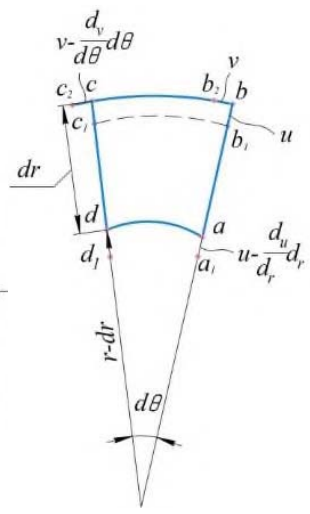

c)

Fig. 2. The scheme of deformation of an infinitesimal element inside a roll (a - the basic design scheme; $b$ - a side view of the main design scheme; $\mathrm{c}$ - a diagram of the deformation of the selected element).

We consider each type of deformation separately. Circumferential deformation occurs as a result of several reasons: as a result of the difference in the displacements of points aand $d$ in the circumferential direction (Figure 2c).

$$
\varepsilon_{\theta}^{(1)}=\frac{b b_{2}-c c_{2}}{b c}=\frac{v-v+\frac{\partial v}{\partial \theta} d \theta}{r d \theta}=\frac{1}{r} \cdot \frac{\partial v}{\partial \theta}
$$

where $\mathrm{v}$ is the amount of movement of an arbitrary point relative to the axis of the roll, $\mathrm{m}$;

risthe radius of arc bc, $\mathrm{m}$;

$d \theta$ - elementary polar angle bounding elementary volume;

$\frac{\partial v}{\partial \theta}$ - relative circumferential deformation;

and the transition of $\operatorname{arc} b c=r d \theta$ to a circle of smaller radius $r '=r-u$, as a result of which the length of the arc becomes equal to $\mathrm{b} 1 \mathrm{cl}=(\mathrm{r}-\mathrm{u}) \mathrm{d} \theta$ and the relative compression is

$$
\varepsilon_{\theta}^{(2)}=\frac{b c-b_{1} c_{1}}{b c}=\frac{r d \theta-(r-u) d \theta}{r d \theta}=\frac{u}{r}
$$

where $\mathrm{u}$ is the amount of movement of an arbitrary point to the center of the roll, $\mathrm{m}$. The total circumferential deformation is equal to

$$
\varepsilon_{\theta}=\varepsilon_{\theta}^{(1)}+\varepsilon_{\theta}^{(2)}=\frac{1}{r} \cdot \frac{\partial v}{\partial \theta}+\frac{u}{r}
$$


Analyzing expression (3), itisseen that the first summand $\frac{1}{r} \cdot \frac{\partial v}{\partial \theta}$ will be small due to the anisotropic properties of baled hay and with a large radius of the roll, and therefore one can neglect it. The relative compression of side $a b$ (Figure $2 \mathrm{c}$ ) is equal to the difference in the displacements of points $a$ and $b$ towards the radius divided by the initial lengths $a b=d r$ :

$$
\varepsilon_{r}=\frac{b b_{1}-a a_{1}}{a b}=\frac{u-\left(u-\frac{\partial u}{\partial r} d r\right)}{d r}=\frac{\partial u}{\partial r}
$$

where $d r$ - increment of vector radius;

$$
\frac{\partial u}{\partial r} \text { - relative radial deformation. }
$$

Our expressions for an infinitely small element in a state of volumetric compression, taking into account the anisotropic properties of hay, are similar to the expressions for a plane stress state. Therefore, the expressions of the direct and inverse Hooke laws are applied for a plane stress state and have the following form [9]:

$$
\varepsilon_{r}=\frac{1}{E}\left(\sigma_{r}-\mu \sigma_{\theta}\right)
$$

where $E$ - modulus of elasticity, $\mathrm{Pa}$;

$\mu$ - Poisson's ratio;

$\sigma_{r}$ - radial stress, Pa;

To compose the conditions for the unambiguity of displacements, we substitute the geometric relations (4) in the formula of the Hooke law for a plane stress state and obtain the following equation:

$$
\varepsilon_{r}=\frac{\partial u}{\partial r}=\frac{1}{E}\left(\sigma_{\theta}-\mu \sigma_{r}\right)
$$

Integrating and solving it, we obtain the final expression for stresses and radial displacement [10]:

$$
\sigma_{r}=\frac{\left(p_{2}-p_{1}\right) k_{1}^{2}}{1-k_{1}^{2}} \cdot \frac{1}{k_{2}^{2}}+\frac{p_{1} k_{1}^{2}-p_{2}}{1-k_{1}^{2}}
$$

where

$$
k_{1}=\frac{R_{b}}{R_{H}}, \quad k_{2}=\frac{r}{R_{\theta}}, \quad R_{\theta} \leq r \leq R_{H}
$$

$k_{1}$ - the ratio of the radial size of the roll with the size of the core);

$k_{2}$ - the ratio of the radial size of the roll with the current radius. 
Pressure $p_{2}$ having some effect on the outside of the roll significantly exceeds elastic pressure of hay $p_{1}$ in the middle of the roll. Therefore, for approximate calculations, one can consider the effect of pressure $p 1$ tending to zero and then the formula for radial stress takes the following form:

$$
\sigma_{r}=\frac{p_{2}}{1-k_{1}^{2}}\left(\frac{k_{1}^{2}}{k_{2}^{2}}-1\right)
$$

The resulting formula expresses the dependence of the radial compression stresses inside the roll on the pressing. It should be noted that the stress values largely depend on the location inside the roll, the highest stresses occur in the periphery of the roll and the smallest ones can be found in the core. It should also be noted that the stresses inside the roll will always be less than the pressures applied when pressing.

The study of the density distribution of stalk feed inside the roll made it possible to establish that the compaction of the roll occurs from the outside due to the radial forces acting from the side of the baling rollers. An analysis of the density distribution inside the roll revealed that the density increases and is distributed exponentially from the periphery to the center of the roll.

Experimental studies have made it possible to obtain values of the density of the roll in various sections, on the basis of which a topographic picture of the density of the roll was created. Using STATISTICA V10 program, a model of the density of pressed hay in a roll was constructed, which is shown in Figure3.

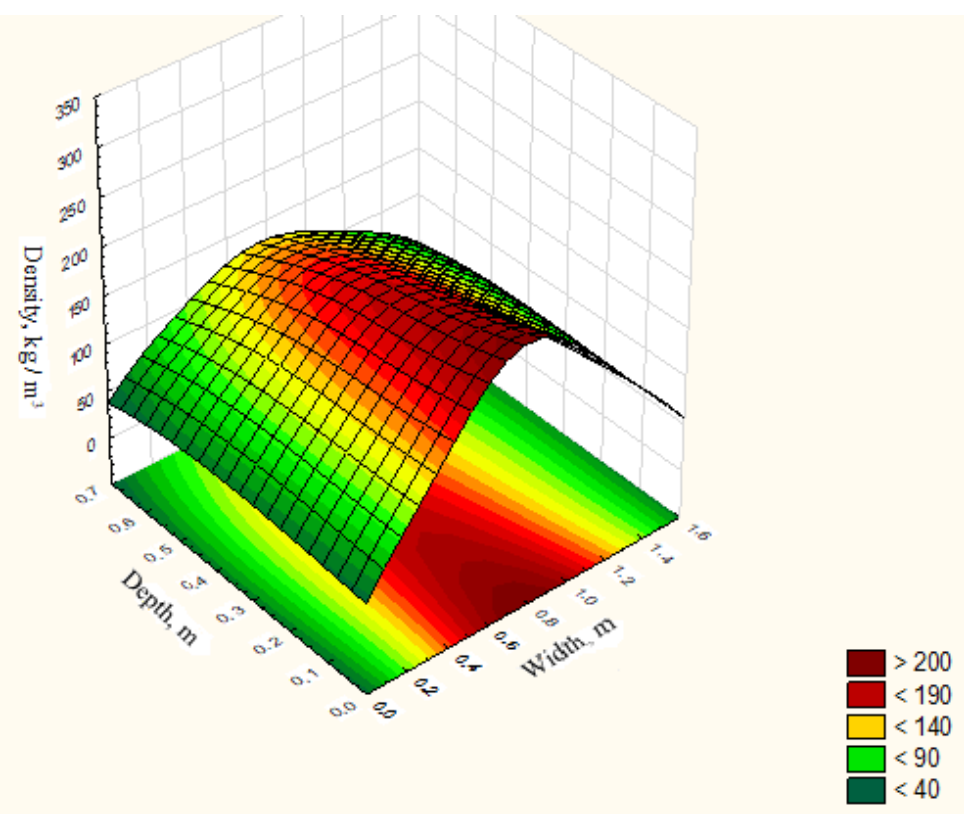

Fig. 3. Distribution of hay density inside the roll.

Statistical analysis of the model showed that the correlation coefficient was $\mathrm{R}=0.87$ and the determination coefficient showing the adequacy of the model was 0.76 .

Analysis of the distribution of hay density inside the roll showed that the density of hay in the middle part of the roll (in width) was 2 to 3 times higher than along its edges, the 
zone of increased density was $0.7 \mathrm{~m}$, which was $44 \%$ of the width of the roll. This dependence is due to the shape of the hay roll that falls into the baler.

To analyze the safety and nutritional properties, hay samples were transferred to an accredited testing laboratory for agrochemical services for agricultural production of the Federal State Institution "Ryazanskaya Station of Agrochemical Service". During the analysis, the following parameters were evaluated: crude and digestible protein, crude fiber, carotene (provitamin A), metabolic energy, the number of colonies of microorganisms and mold fungi was also estimated (Table 1).

Table 1. Qualitative parameters of hay samples.

\begin{tabular}{|c|c|c|c|}
\hline Parameter & Units & $\begin{array}{c}\text { Baled hay roll } \\
\text { center }\end{array}$ & $\begin{array}{c}\text { Baled hay roll } \\
\text { edge }\end{array}$ \\
\hline Energy feed units & - & 0.828 & 0.821 \\
\hline Exchange energy & $\mathrm{mJ}$ & 8.28 & 8.21 \\
\hline Dry matter & $\mathrm{g} / \mathrm{kg}$ & 885.0 & 882.0 \\
\hline Crude protein & $\mathrm{g} / \mathrm{kg}$ & 92.8 & 109.6 \\
\hline Digestible protein & $\mathrm{g} / \mathrm{kg}$ & 46.4 & 66.2 \\
\hline Crude fiber & $\mathrm{g} / \mathrm{kg}$ & 272 & 275.5 \\
\hline Carotene & $\mathrm{mg} / \mathrm{kg}$ & 23 & $3 * 10^{6}$ \\
\hline $\begin{array}{c}\text { The total number of } \\
\text { microorganisms }\end{array}$ & $\mathrm{CFU}$ & $5 * 10^{5}$ & 30.0 \\
\hline $\begin{array}{c}\text { The number of mold } \\
\text { fungi colonies }\end{array}$ & $\mathrm{CFU}$ & 50.0 & \\
\hline
\end{tabular}

Analyzing the data on the nutritional value of hay, one can conclude that the hay of the peripheral part of the roll was more nutritious than the central one. Firstly, one of the most important parameters of nutritional value of the feed is the content of crude protein. So the hay located closer to the outer part of the roll contained more crude protein than that in the central part $-18.10 \%$. The content of digestible protein in the extreme layers also exceeded the hay in the middle part by $42.67 \%$.

It is worth noting that the protein nutritional value of feed is one of the most important parameters of productivity in farm animals. In addition, the protein supplied with the feed serves as a material for the formation of new cells of the animal's body tissues, is one of the sources of energy, etc. As the analysis showed, the difference in crude fiber in the center and outer layers of the roll was not significant. In terms of carotene content, hay located in the center of the roll significantly exceeded the second option. This parameter was at the level of $23 \mathrm{mg} / \mathrm{kg}$, against $18 \mathrm{mg} / \mathrm{kg}$, which was $21.73 \%$ more.

According to the content of microorganisms in the harvested hay, their significant quantitative excess was at the outer part of the roll - $3 * 106 \mathrm{CFU}$, which is primarily associated with the features of the technologies for harvesting, transporting and storing the baled hay.

However, in terms of the number of mold fungi, the outer layers of the roll were less infected with pathogenic microorganisms, which suggests that the most favorable conditions for the development of mold colonies were formed in the center of the roll. The reason for this may be a feature of the device of the bale chamber, thus, the core of the roll had a lower density compared to its periphery, thereby creating better conditions for air and moisture. 


\section{Conclusion}

Theoretical and experimental studies show that in the process of roll formation, zones with different densities of stalked hay particles arise: for example, the core of the roll has a significantly lower density than its peripheral part. The unevenness of the hay roll into the bale chamber cannot be completely eliminated by stress relaxation during the formation and subsequent storage of the roll.

The formation of zones with insufficient density leads to a decrease in the quality parameters of hay, in particular its nutritional value, and also creates more favorable conditions for the development of mold colonies, which leads to the formation of mycotoxins dangerous for the animal and human organism.

In this connection, in order to increase the safety of baled hay, it is rational to apply the operations of leveling the roll before baling, as well as treat the hay with preservatives when baling.

\section{References}

1. A. Uijttewaal, S. Chapuis, G. Crocq, P. Lépée, Advances in methods for harvesting and storing forage legumes, Article@Quoi de neufenmatière derécolte et conservation des légumineusesfourragères, Fourrages, 227, pp. 157-166 (2016)

2. J. Fang, H. Li, J. Wang, M. Yang, Z. Zong, Zhang, Compression and stress relaxation characteristics of Alfalfa during Rotary Compression, BioResources, 14 (2), pp. 38603872 (2019) DOI: 10.15376/biores.14.2.3860-3872

3. X. Wei, S. Shangli, Q. Juan, V.R. Squires, H. Limin, Z. Wenyu, W. Xingzhong, W. Yongfu, N. Xingze, L. Changbo, L. Peng, C. Shaofang, Effect of different processing methods on the quality of Alfalfa Hay, Journal of Animal and Veterinary Advances, 12 (6), pp. 689-693 (2013) DOI: 10.3923/javaa.2013.689.693

4. F.D. Román, O. Hensel Numerical simulations and experimental measurements on the distribution of air and drying of roundhay bales, Biosystems Engineering, 122, pp. 1-15 (2014) DOI: 10.1016/j.biosystemseng.2014.03.008

5. D. Gao, D. Wang, J. Li, Y. Liu, X. Qiao, Design and test of logarithmic spiral round baler chamber. NongyeJixieXuebao/Transactions of the Chinese Society for Agricultural Machinery, 46 (7) (2015) DOI: 10.6041/j.issn.1000-1298.2015.07.018

6. J. Fang, Y. Zhang, M. Yang, A. Wang, J. Wang, D. Liu, J. Gao, H. Li,. Stress relaxation behavior and modeling of alfalfa during rotary compression. NongyeGongchengXuebao, Transactions of the Chinese Society of Agricultural Engineering, 34 (16), pp. 50-56 (2018) DOI: 10.11975/j.issn.1002-6819.2018.16.007

7. J. Lei, D. Wang, Q. Zhang, X. Yang, L. Li, C. Li, Experiment on stress relaxation characteristics of intact rice straw during rotary compression. NongyeGongchengXuebao, Transactions of the Chinese Society of Agricultural Engineering, 31 (8), pp. 76-83 (2015) DOI: 10.3969/j.issn.1002-6819.2015.08.012

8. V. I. Osobov Mechanical technology of feed. Moscow, Kolos (2009)

9. G. S. Vardanyan, V. I. Andreev, N. M. Atarov, A. A. Gorshkov Resistance of materials with the basics of elasticity and plasticity. Ed. G S Vardanyan and N M Atarova. - 2nd ed., Rev. and add. Moscow, INFRA-M (2011)

10. Kozlov G, et al. E3S Web of Conferences 175, 12015 (2020) doi:10.1051/e3sconf/202017512015 